\title{
Can Hydraulic Barriers Stop the Spread of the Round Goby?
}

by Jan Jeffrey Hoover, S. Reid Adams, and K. Jack Killgore

BACKGROUND: The round goby, Neogobius melanostomus, a native of Eurasia, is spreading throughout the waters of North America (Figure 1). Native to the Black Sea and Caspian Sea systems, the round goby appeared in the St.Clair River, ONT-MI in 1990, and subsequently in the Great Lakes during 1993-1996 (Charlebois et al. 1997). Particular concern exists for the population in southern Lake Michigan and the Calumet River, which is spreading west via the Cal-Sag Channel towards the Des Plaines River (Moy 1997). Penetration by the round goby into the Mississippi River system, or any large river system, would allow virtually unlimited spread throughout large geographic areas. Its high rate of dispersal (e.g., all five Great Lakes in only 5 years) is particular cause for concern (Jude 1997).

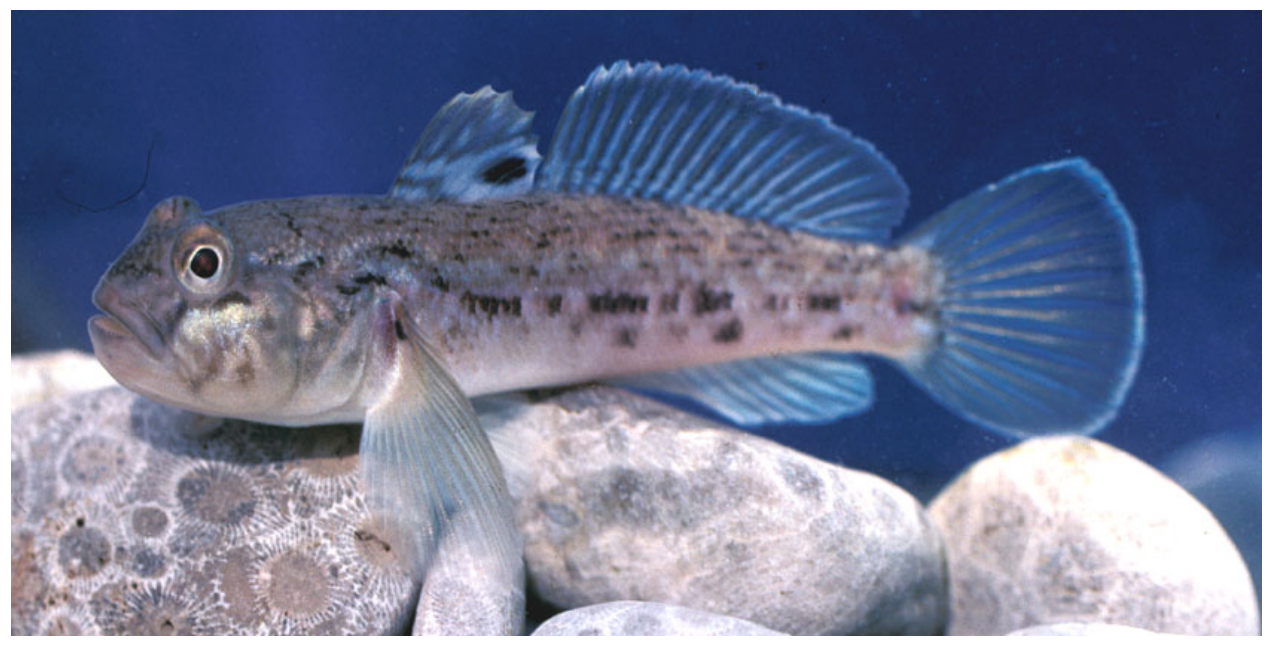

Figure 1. Round goby (Neogobius melanostomus). Photograph provided by David Jude, School of Natural Resources and the Environment, University of Michigan

This benthic species, although small, is highly aggressive toward native fishes, especially the mottled sculpin (Cottus bairdi), which is unable to effectively defend the cavities it normally inhabits from gobies (Dubs and Corkum 1996). The round goby is also aggressive towards larger, pelagic species such as rock bass (Ambloplites rupestris) and smallmouth bass (Micropterus dolomieui) (Wickett and Corkum 1998), as well as smaller, benthic species like darters, Etheostoma spp. (Jude 1997). Containment of the round goby has been identified as a priority by several agencies, including the U.S. Army Corps of Engineers and the U.S. Fish and Wildlife Service. The round goby could be contained by use of ichthyocides, electricity, or by hydraulics. The last of these is environmentally benign and safe, but efficacy is unknown.

PURPOSE: To evaluate potential for hydraulic containment of round gobies, three questions were addressed in a series of laboratory experiments: 
- What are the station-holding capabilities of round gobies?

- How is station-holding endurance influenced by substrate?

- Are goby movements effectively contained by hydraulic barriers?

Round gobies were tested in a series of laboratory experiments to determine whether hydraulic containment of populations was possible. Station-holding endurance models, critical station-holding velocity tests, and a small, low-velocity barrier in a simulated stream all indicated that containment was feasible, but that barrier specifications would have to be adjusted to local conditions (bottom topography, substrate size, water temperature).

METHODS: Specimens were obtained by angling during the summer of 1998 and sent by overnight delivery to the Waterways Experiment Station. They were maintained in 300-L Living Stream fiberglass aquaria (model 510, Frigid Units, Toledeo, $\mathrm{OH}$ ) filled with dechlorinated tap water. Tanks provided slow $(<10 \mathrm{~cm} / \mathrm{s})$ rectilinear flow and constant water temperature. Tank bottoms were left bare but pieces of PVC pipe were used to provide bottom cover. Gobies were fed twice daily: frozen bloodworms (Chironomidae), dry salmon pellets (Silver Cup Salmon Crumbles, Nelson and Sons, Inc., Murray, UT). Light-dark cycle approximated natural conditions.

Predictive Endurance models - Station-holding endurance was evaluated in a propeller-driven, 100-L Blazka swim tunnel (Beamish 1978) using protocol developed for another benthic fish, juvenile pallid sturgeon (Adams et al. 1999). Tunnel had a working section $39 \mathrm{~cm}$ long, $15 \mathrm{~cm}$ diameter, with two sets of flow filters to promote microturbulent, rectilinear flow. Tunnel velocities were measured and calibrated to specific rheostat settings on the electric motor using a Marsh-McBirney flow meter.

Thirty-six hours prior to testing, gobies were isolated from the population and not fed to achieve postabsorptive state. At time of testing, a fish was transported to the swim tunnel in a water-filled PVC cylinder, habituated in the tunnel for 1 hour at $5 \mathrm{~cm} / \mathrm{s}(30 \mathrm{~min})$ and $10 \mathrm{~cm} / \mathrm{s}(30 \mathrm{~min})$. Following habituation, water speed was increased rapidly (2-4 sec) to test velocity. The fish was observed for station holding, and time to fatigue was recorded. If a goby was able to maintain position at a particular speed for $200 \mathrm{~min}$ (or more), then that speed was considered to represent sustained stationholding. If the fish was unable to maintain a particular speed indefinitely (i.e., it fatigued), the speed represented prolonged $(0.5$ to $200 \mathrm{~min})$ or burst station holding $(<0.5 \mathrm{~min})$. Fish were allowed to maintain station by swimming or by substrate appression, and no attempt was made to alter behavior. Fish were considered fatigued when they could no longer swim or maintain position without bracing against or becoming impinged upon the downstream screen of the working section of the tunnel after which they would not respond to mechanical stimulation (gentle prodding). Test velocities ranged from $15-75 \mathrm{~cm} / \mathrm{s}$.

Gobies were tested only once. After testing, total length (TL) of the fish (to the nearest $1 \mathrm{~mm}$ ) and weight (to the nearest $0.01 \mathrm{~g}$ ) were recorded. Gender was recorded only for those fish in which the shape of the urogenital papillae could be definitively categorized as male or female (based on Charlebois et al. (1996)). A small series of fish $(\mathrm{N}=39)$ was tested at $20{ }^{\circ} \mathrm{C}$, another larger series $(\mathrm{N}=111)$ at $17{ }^{\circ} \mathrm{C}$.

The predictive relationship between water velocity and fish size (independent variables) and endurance (dependent variable) was quantified using linear and polynomial regression techniques 
(Statistical Analysis Systems, Carey, NC). The model that accounted for the highest degree of data set variance $\left(r^{2}\right)$ was chosen. Swimming trials in which fish did not fatigue (i.e., sustained swimming) were excluded from models. Length-weight relationships were also analyzed using $\log _{10}$ conversions of data and linear regression.

Influence of substrate roughness - Critical swimming/station-holding speed was determined over various substrates in the Blazka swim tunnel. The tunnel was modified with interchangeable horizontal Plexiglas inserts that rested on the bottom of the working section of the tunnel. Inserts were bare, covered with a layer of sand, or covered with a layer of gravel $(5-10 \mathrm{~mm})$, simulating substrates that are smooth (e.g., bedrock), fine, or coarse. Individual fish were introduced into the tunnel, habituated, and subjected to increasing water velocity (at $5 \mathrm{~cm} / \mathrm{s}$ increments) every 10 minutes until fatigued. Time at the fatigue velocity was recorded.

Critical station-holding speed was calculated according to Brett (1964):

$$
U_{c r i t}=U_{1}+\left(T_{1} / T_{2} \times U_{2}\right)
$$

in which $\mathrm{U}_{\text {crit }}$ is the 10-min critical station-holding speed, $\mathrm{U}_{1}$ is the highest water velocity maintained for the prescribed time period, $T_{1}$ is the duration of swimming at the fatigue velocity, $T_{2}$ is the prescribed period of swimming (or $10 \mathrm{~min}$ ), and $U_{2}$ is the velocity increment $(5 \mathrm{~cm} / \mathrm{s}$ ). Fish were tested once. Seven fish were tested for each substrate insert. Differences among substrates were evaluated using MANOVA and the Tukey HSD test (Statistica StatSoft Inc., Tulsa, OK).

Physical model of a hydraulic barrier - Short-term containment of round gobies was demonstrated in a laboratory stream with a simulated "containment field." This laboratory stream is an elliptical channel, shaped like a racetrack and made of aquamarine fiberglass (Model SM, Frigid Units, Toledo Ohio). It is $5.5 \mathrm{~m}$ long. Channel is $31 \mathrm{~cm}$ wide and water is $26.5 \mathrm{~cm}$ deep. Total water volume is 1000 L. Water is drawn continuously from the surface. It is piped into a filter-aerator consisting of a 20-L bucket with a porous bottom, containing floss, carbon, and foam. Filtered water collects in a reservoir with a water volume of $236 \mathrm{~L}$ and containing a Little Giant submersible pump (Model 3E-34N, Oklahoma City, OK), which returns water to the channel. Water enters the channel from the reservoir through a PVC pipe generating the hydraulic barrier. The inflow pipe is $30 \mathrm{~cm}$ long, perpendicular to the long axis of the channel, and is suspended $4 \mathrm{~cm}$ above the channel bottom. This position allows for near-uniform flow throughout the channel and in the event of interrupted power, prevents the channel from draining completely. Water velocity is $29.5 \mathrm{~cm} / \mathrm{s} 1 \mathrm{~m}$ from the barrier, $13.5 \mathrm{~cm} / \mathrm{s} 2 \mathrm{~m}$ from the barrier, and $9.0 \mathrm{~cm} / \mathrm{s} 3 \mathrm{~m}$ from the barrier. A screen placed $3 \mathrm{~m}$ "downstream" from the barrier defines the lower limit of the containment field. Six trials were conducted: three controls using nonflowing water and three treatments using flowing water. In each trial, nine gobies were released within the containment field. The number of individuals crossing the barrier was determined after $24 \mathrm{hr}$. 


\section{RESULTS}

Size of gobies and behavior - Gobies tested ranged in size from $43-154 \mathrm{~mm}$ TL $(\mathrm{N}=150)$. Individuals identifiable as males were $72-154 \mathrm{~mm}$ TL $(\mathrm{N}=63)$; females were $75-136 \mathrm{~mm}$ TL $(\mathrm{N}=$ 34). Length-weight relationship for all fish was:

$$
\log _{10} \text { Weight }=3.13\left(\log _{10} \text { Length }\right)-5.13, \mathrm{r}^{2}=0.98, \mathrm{p}<0.0001
$$

This relationship was not substantially different than models generated for males,

$$
\log _{10} \text { Weight }=3.04\left(\log _{10} \text { Length }\right)-4.94, r^{2}=0.97, p<0.0001
$$

or for females,

$$
\log _{10} \text { Weight }=2.83\left(\log _{10} \text { Length }\right)-4.53, r^{2}=0.96, p<0.0001
$$

Gobies in all three experiments spent very little time ( $<20$ percent) swimming in the water column, or skimming along the surface of the bottom. Instead, they hunkered close to the bottom, appresssing themselves to it, as they turned about or darted forward and backward.

Predictive endurance models - Stepwise multiple regression analyses indicated that for both water temperatures, endurance was negatively correlated with water velocity and positively correlated with length of fish. There were notable differences in swimming speeds between temperatures. At $17{ }^{\circ} \mathrm{C}$, the relationship was:

$$
\log _{10} \text { Endurance }=-0.027(\text { Velocity })+0.007(\text { Length })+0.516, r^{2}=0.62, p<0.0001
$$

At $20{ }^{\circ} \mathrm{C}$, the relationship was:

$$
\log _{10} \text { Endurance }=-0.028(\text { Velocity })+0.005(\text { Length })+0.940, r^{2}=0.67, p<0.0001
$$

At both water temperatures, water velocity was the primary variable accounting for endurance (partial $\left.r^{2}>0.55\right)$. The influence of fish size in the multiple regression models, although statistically significant $(\mathrm{p}<0.09)$, was relatively low (partial $\mathrm{r}^{2}<0.07$ ). To minimize the influence of fish size on endurance data, however, data were analyzed separately for small fish $(<90 \mathrm{~mm}$ TL) and large fish (>90 mm TL).

At $17{ }^{\circ} \mathrm{C}$, small gobies exhibited sustained station holding at $15 \mathrm{~cm} / \mathrm{s}$, prolonged station holding $(0.5$ $44 \mathrm{~min}$ ) at $20-50 \mathrm{~cm} / \mathrm{s}$, and burst station-holding at $55-75 \mathrm{~cm} / \mathrm{s}$ (Figure 2). Large gobies exhibited sustained swimming at $20 \mathrm{~cm} / \mathrm{s}$, prolonged swimming $(0.5-72 \mathrm{~min})$ at $20-50 \mathrm{~cm} / \mathrm{s}$, and mostly burst station holding at $55-75 \mathrm{~cm} / \mathrm{s}$. Although endurance values of the two size groups overlapped at most water velocities, larger fish typically had greater endurance than smaller fish. At $20{ }^{\circ} \mathrm{C}$, sustained station holding was not observed (Figure 3 ). For small gobies, prolonged station holding (0.5-61 min) was observed at $15-55 \mathrm{~cm} / \mathrm{s}$, burst at $60 \mathrm{~cm} / \mathrm{s}$. Only 12 large fish were run at $20^{\circ} \mathrm{C}$ and none of these were tested at water velocities $<40 \mathrm{~cm} / \mathrm{s}$. Data suggest that larger fish had greater endurance than the smaller fish over this range of water velocities. Overall, station-holding endurance at lower water velocities $(<30 \mathrm{~cm} / \mathrm{s})$ was higher at the cooler temperature; endurance at higher water velocities 
( $>30 \mathrm{~cm} / \mathrm{s}$ ) was higher at the warmer temperature. Definitive statements regarding differences in swimming performance at different water temperatures cannot be made at this time, since tests were discontinued at $20{ }^{\circ} \mathrm{C}$ due to apparent stress experienced by gobies at that temperature (based on aberrant behavior and post-test mortality). Because endurance decreased curvilinearly with increased water velocity, polynomial models were used to describe the relationship between the two variables (Table 1).

Influence of substrate roughness - Fish exhibited improved station-holding times with increased roughness of the substrate. Mean critical station-holding speeds (and standard deviations) were 20.7 (3.4), 42.4 (4.6), and 52.5 (2.0) cm/s on Plexiglas, sand, and gravel substrates respectively. Significant differences existed among the values $(\mathrm{df}=2 / 18, \mathrm{~F}=147.96, \mathrm{p}<0.0001)$. Each mean value was statistically different from each of the other values $(\mathrm{p}<0.0003)$. Differences among values were not attributable to differences in size of fish among treatments. Mean sizes of fish ranged from 77.4-78.9.

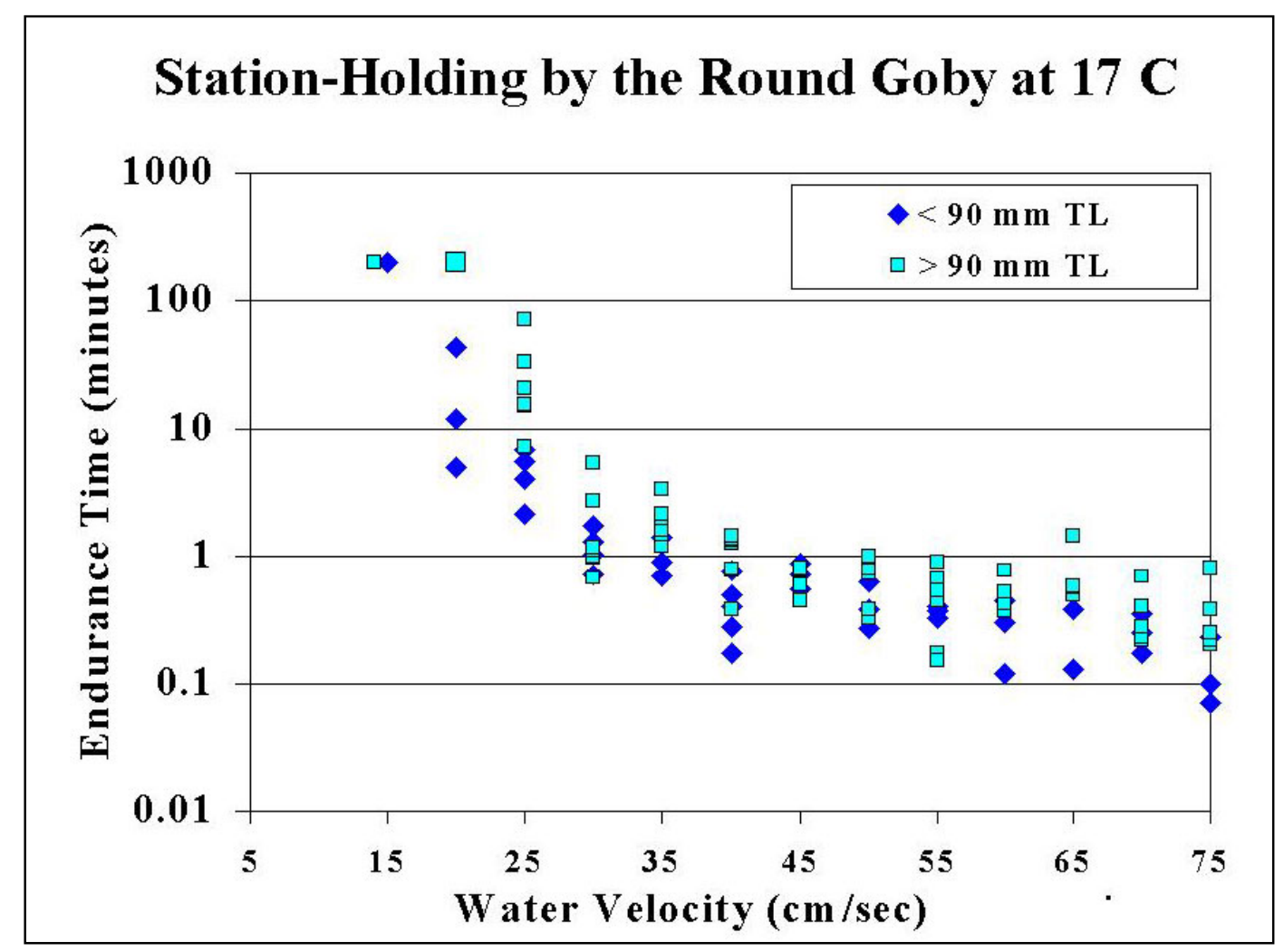

Figure 2. Station-holding by two size classes of round gobies in cool water 


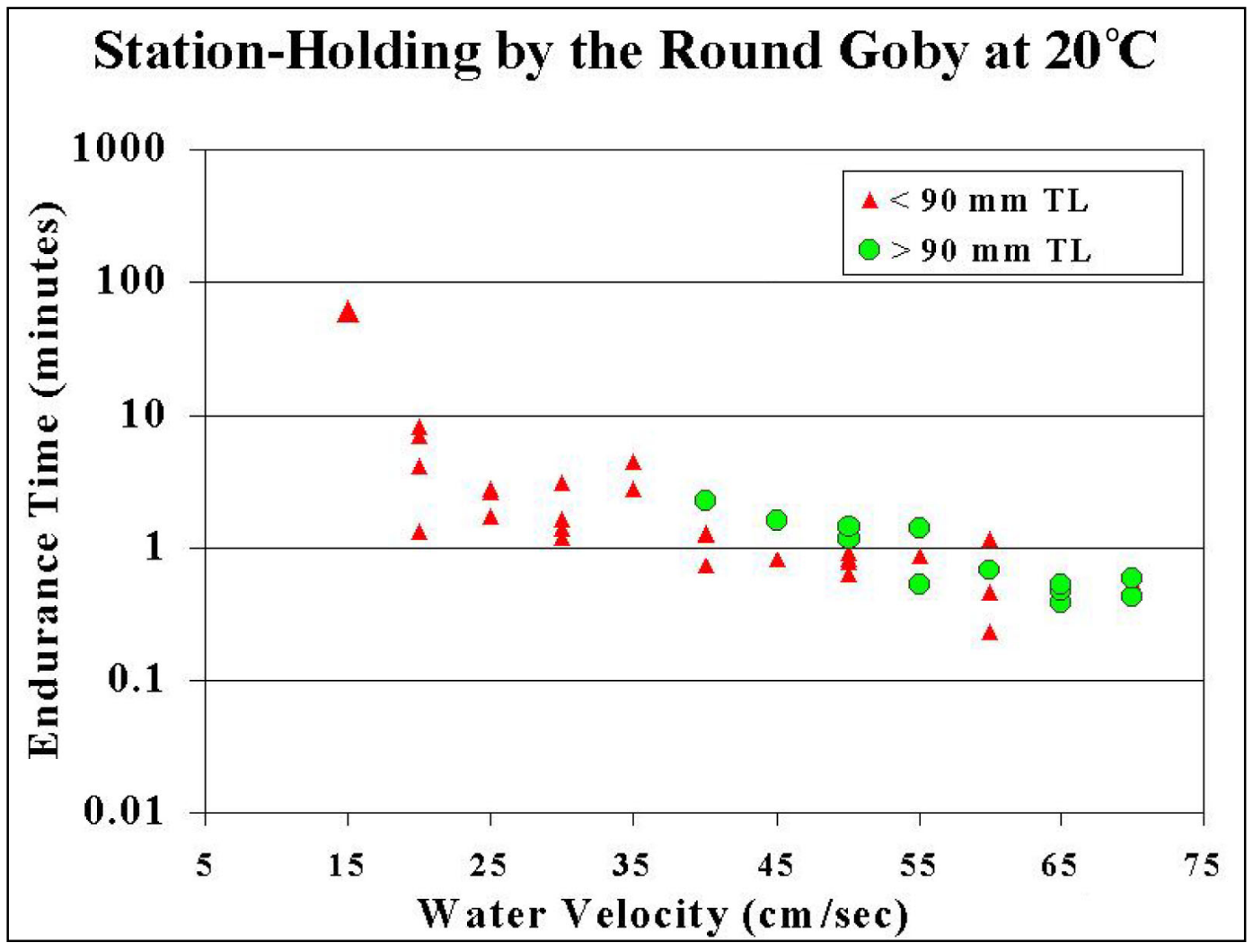

Figure 3. Station-holding by two size classes of round goby in warm water

\section{Table 1 \\ Polynomial Regression Models Relating Endurance Time of Round Goby (Minutes) to Water Velocity (in $\mathrm{cm} / \mathrm{s})^{1}$}

\begin{tabular}{||l|l|l|l|l|l|}
\hline \hline $\begin{array}{l}\text { Temperature } \\
{ }^{\circ} \mathbf{C}\end{array}$ & $\begin{array}{l}\text { Size } \\
\text { Class }\end{array}$ & Model & $\mathbf{N}$ & $\mathbf{R}^{2}$ & $\mathbf{p}$ \\
\hline \hline 17 & Small & $\log _{10}$ Time $=0.0007\left(\mathrm{Vel}^{2}\right)-0.0969(\mathrm{Vel})+2.5471$ & 41 & 0.79 & $<0.0001$ \\
\hline 17 & Large & $\log _{10}$ Time $=0.0009\left(\mathrm{Vel}^{2}\right)-0.1156(\mathrm{Vel})+3.2207$ & 63 & 0.67 & $<0.0001$ \\
\hline 20 & Small & $\log _{10}$ Time $=0.0006\left(\mathrm{Vel}^{2}\right)-0.0727(\mathrm{Vel})+1.9955$ & 27 & 0.67 & $<0.0001$ \\
\hline 20 & Large & $\log _{10}$ Time $=0.0004\left(\mathrm{Vel}^{2}\right)-0.0676(\mathrm{Vel})+2.4848$ & 12 & 0.82 & 0.0005 \\
\hline \hline
\end{tabular}

${ }^{1}$ Small fish were 65-88 mm TL; large fish were 91-154 mm TL. Round gobies were tested over a range of $15-75 \mathrm{~cm} / \mathrm{s}$ with the exception of large fish run at $20^{\circ} \mathrm{C}$, for which data were obtained only at $40-70 \mathrm{~cm} / \mathrm{s}$.

Physical model of a hydraulic barrier - Gobies were contained by the small-scale physical model of a hydraulic barrier. During three trials, when the barrier was non-operational, gobies freely distributed throughout the experimental channel. During three trials, when the barrier was operational, all gobies were contained behind the barrier in two trials, despite frequent, prolonged approaches of the barrier. During the third trial, a goby crossed the barrier and had escaped the containment field.

DISCUSSION: Size of gobies was comparable to previous reports and is probably representative of the population in the Great Lakes Region. Size range was nearly identical to that reported for Calumet 
Harbor, approximately 60-145 mm TL, as was the similarity in weights of males and females (Charlebois et al. 1997).

Gobies are not powerful swimmers, maintaining station primarily by pressing their bodies to the substrate, and their ability to hold station is positively correlated with substrate roughness or size. A hydraulic barrier, to effectively contain round gobies, would not only have to provide sufficiently high water velocities over a sufficiently great distance to exceed their physiological endurance, but would also have to be located in a relatively straight-sided channel with smooth substrate so as to exceed their behavioral mechanisms for avoiding or withstanding flow. If such channels exist in local areas of concern, then the likelihood of containment seems promising. If such a channel does not exist, than hydraulic containment would have to rely on elevated water velocities (e.g., greater than $75 \mathrm{~cm} / \mathrm{s}$ ) or prolonged distances of moderate velocity generation.

ACKNOWLEDGMENTS: This project was funded by the U.S. Army Engineer Chicago District. Bradley Lewis assisted in the laboratory. Phil Moy arranged for delivery of fish. Permission to publish this document was granted by the Chief of Engineers.

POINTS OF CONTACT: For additional information, contact Dr. Jan Hoover, (601) 634-3996, Jan.J.Hoover@erdc.usace.army.mil, or the Manager of the Aquatic Nuisance Species Research Program, Dr. Al Cofrancesco, (601) 634-3182, Al.F.Cofrancesco@erdc.usace.army.mil. This technical note should be cited as follows:

Hoover, J. J., Adams, S. R., and Killgore, K. J. (2003). "Can hydraulic barriers stop the spread of the round goby?" ANSRP Technical Notes Collection (TN ANSRP03-1), U.S. Army Engineer Research and Development Center, Vicksburg, MS. www.wes.army.mil/el/ansrp

\section{REFERENCES}

Adams, S. R., Parsons, G. R., Hoover, J. J., and Killgore, K. J. (date). “Observations of swimming ability in shovelnose sturgeon (Scaphirhynchus platorynchus).” J. Freshwater Ecol. 12: 631-633.

Adams, S. R., Hoover, J. J., and Killgore, K. J. (1999). "Swimming endurance of juvenile pallid sturgeon, Scaphirhynchus albus." Copeia 802-807.

Beamish, F. W. H. (1978). “Swimming capacity,” Fish physiology, Vol. 7, W. S. Hoar and D. J. Randall, eds, Academic Press, New York.

Brett, J. R. (1964). "The respiratory metabolism and swimming performance of young sockeye salmon." J. Fish. Res. Bd. Can. 21: 1522-1529.

Charlebois, P. M., Marsden, J. E., Goettel, R. G., Wolfe, R. K., Jude, D. J., and Rudnika, S. (1997). “The round goby, Neogobius melanostomus (Pallas), a review of European and North American Literature." Illinois-Indiana Sea Grant program and Illinois Natural History Survey, INHS Special Publication 20.

Dubs, D. O. L., and Corkum, L. D. (1996). "Behavioral interactions between round gobies (Neogobius melanostomus) and mottled sculpins (Cottus bairdi).” J. Great Lakes Res. 22 838-844.

Jude, D. J. (1997). "Round gobies: cyberfish of the third millennium.” Great Lakes Research Review 3[1]: 27-34.

Moy, P. (1997). "An ANS dispersal barrier for the Great Lakes and Mississippi River Basins." Great Lakes Panel on Aquatic Nuisance Species ANS Update 3[4]: 1. 
Wickett, R. G., and Corkum, L. D. (1998). "You have to get wet: A case study of the nonindigenous Great Lakes fish, round goby." Fisheries 23[12]: 26-27.

NOTE: The contents of this technical note are not to be used for advertising, publication, or promotional purposes. Citation of trade names does not constitute an official endorsement or approval of the use of such products. 